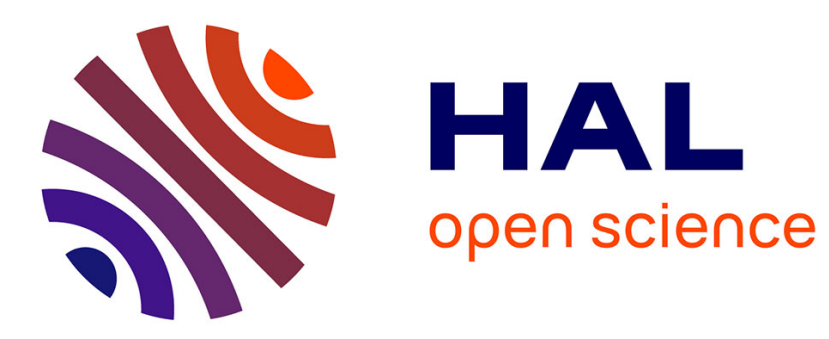

\title{
Oceanic lithosphere-asthenosphere boundary from surface wave dispersion data
}

Gael Burgos, J.P. Montagner, E. Beucler, Yann Capdeville, A. Mocquet, M. Drilleau

\section{- To cite this version:}

Gael Burgos, J.P. Montagner, E. Beucler, Yann Capdeville, A. Mocquet, et al.. Oceanic lithosphereasthenosphere boundary from surface wave dispersion data. Journal of Geophysical Research: Solid Earth, 2013, pp.1079-1093. 10.1002/2013JB010528 . insu-01391672

\section{HAL Id: insu-01391672 https://hal-insu.archives-ouvertes.fr/insu-01391672}

Submitted on 3 Nov 2016

HAL is a multi-disciplinary open access archive for the deposit and dissemination of scientific research documents, whether they are published or not. The documents may come from teaching and research institutions in France or abroad, or from public or private research centers.
L'archive ouverte pluridisciplinaire HAL, est destinée au dépôt et à la diffusion de documents scientifiques de niveau recherche, publiés ou non, émanant des établissements d'enseignement et de recherche français ou étrangers, des laboratoires publics ou privés. 


\section{Journal of Geophysical Research: Solid Earth}

\author{
RESEARCH ARTICLE \\ 10.1002/2013JB010528 \\ Key Points: \\ - The anisotropic parameters inverted \\ from surface waves are sensitive \\ to $L A B$ \\ - The shear velocity and azimuthal \\ anisotropy proxies show \\ age-dependent patterns \\ - The radial anisotropy proxy presents \\ a subhorizontal pattern as \\ age increases
}

Correspondence to:

G. Burgos,

burgos@ipgp.fr

\section{Citation:}

Burgos, G., J.-P. Montagner, E. Beucler,

Y. Capdeville, A. Mocquet, and

M. Drilleau (2014), Oceanic lithosphere/asthenosphere boundary

from surface wave dispersion data,

J. Geophys. Res. Solid Earth, 119,

1079-1093, doi:10.1002/2013JB010528.

Received 18 JUL 2013

Accepted 27 DEC 2013

Accepted article online 4 JAN 2014

Published online 7 FEB 2014

\section{Oceanic lithosphere-asthenosphere boundary from surface wave dispersion data}

\author{
G. Burgos ${ }^{1}$, J.-P. Montagner ${ }^{1}$, E. Beucler ${ }^{1}$, Y. Capdeville ${ }^{1}$, A. Mocquet ${ }^{2}$, and M. Drilleau ${ }^{2}$ \\ ${ }^{1}$ Institut de Physique du Globe de Paris, Paris, France, ${ }^{2}$ Université de Nantes, Nantes, France
}

Abstract According to different types of observations, the nature of lithosphere-asthenosphere boundary (LAB) is controversial. Using a massive data set of surface wave dispersions in a broad period range (15-300 s), we have developed a three-dimensional upper mantle tomographic model (first-order perturbation theory) at the global scale. This is used to derive maps of the LAB from the resolved elastic parameters. The key effects of shallow layers and anisotropy are taken into account in the inversion process. We investigate $L A B$ distribution primarily below the oceans, according to different kinds of proxies that correspond to the base of the lithosphere from the shear velocity variation at depth, the amplitude radial anisotropy, and the changes in azimuthal anisotropy $\mathrm{G}$ orientation. The estimations of the LAB depth based on the shear velocity increase from a thin lithosphere $(\sim 20 \mathrm{~km})$ in the ridges, to a thick old-ocean lithosphere $(\sim 120-130 \mathrm{~km})$. The radial anisotropy proxy shows a very fast increase in the LAB depth from the ridges, from $\sim 50 \mathrm{~km}$ to the older ocean where it reaches a remarkable monotonic subhorizontal profile $(\sim 70-80 \mathrm{~km})$. The LAB depths inferred from the azimuthal anisotropy proxy show deeper values for the increasing oceanic lithosphere ( 130-135 km). The difference between the evolution of the LAB depth with the age of the oceanic lithosphere computed from the shear velocity and azimuthal anisotropy proxies and from the radial anisotropy proxy raises questions about the nature of the $L A B$ in the oceanic regions and of the formation of the oceanic plates.

\section{Introduction}

The concept of the lithosphere and asthenosphere, and therefore of the lithosphere-asthenosphere boundary (hereafter referred to as the LAB), was first evoked by Barrell [1914] and then extended by Daly [1940]. However, it remains very elusive, as different geophysical fields have proposed different definitions. In seismology, according to the type of data (e.g., surface waves, receiver functions) or the parameterization (e.g., isotropic, anisotropic medium), contradictory results can be obtained. The LAB is considered to be a key control point in the various geophysical systems.

The LAB can be defined as the depth change of different parameters [e.g., Eaton et al., 2009]. It is associated with a change in rheology, which is underlined by the strain rate change as a function of the depth above a maximum in the asthenosphere, while the elastic lithosphere jointly moves with the plate. As a part of the adiabatic convecting mantle, the LAB within the upper thermal boundary layer can be considered as the limit between a conductive lithosphere and a convective asthenosphere. The LAB is classically associated with the depth of the $1300^{\circ} \mathrm{C}$ isotherm [Artemieva, 2006]. A chemical composition change has also been proposed to produce the $L A B$, through the water content, which produces a limit between the hydrated or dehydrated mantle and presence of fractional melt [Karato, 2012]. Also, the LAB can be defined from electromagnetic data, as associated with a decrease in electrical resistivity from the high values in the lithosphere to the low values in the asthenosphere, [see Jones et al., 2001; Moorkamp et al., 2010].

The LAB inferred from seismological data is commonly defined as the boundary between the high-velocity lid corresponding to the lithosphere and the low-velocity zone corresponding to the asthenosphere. The meaning of the lid and the low-velocity zone have evolved in the past from partial melting processes [Gutenberg, 1959; Kawakatsu et al., 2009] to mineral physics considerations [Anderson and Sammis, 1969], chemistry changes [Regan and Anderson, 1984], and the presence of hydrated phases [Karato, 2012]. Recently, some receiver function studies of both $S p$ and $P s$ converted phase data showed coherent negative velocity drops beneath eastern Australia [Ford et al., 2010] and eastern North America [Rychert et al., 2007] associated with the LAB and a midlithosphere boundary. In northern Tibet [Kumar et al., 2006], only found a 


\begin{tabular}{|c|c|c|c|c|}
\hline \multirow[b]{2}{*}{ Data Set } & \multicolumn{2}{|c|}{ Rayleigh Waves } & \multicolumn{2}{|c|}{ Love Waves } \\
\hline & $\Delta T(\mathrm{~s})$ & $N_{p}$ & $\Delta T(\mathrm{~s})$ & $N_{p}$ \\
\hline $\operatorname{IPGP}\left(C_{R}\right)$ & $44-315$ & $9292^{b}$ & - & - \\
\hline Harvard $\left(C_{R^{\prime}}, C_{L}\right)$ & $35-150$ & 37738 & $35-150$ & 23227 \\
\hline $\operatorname{Utrecht}\left(C_{R}, C_{L}\right)$ & $35-175$ & 63628 & $35-174$ & 45179 \\
\hline Boulder $\left(U_{R^{\prime}} U_{L}\right)$ & $16-200$ & 76580 & $16-150$ & 47021 \\
\hline
\end{tabular}

negative velocity drop for the $L A B$. These studies have mainly reported $L A B$ depths for continents that are in the range of the estimates from surface wave dispersion curves [Fishwick, 2010; Pasyanos, 2010].

Considering the shear velocity parameter, the LAB depth can be defined by the transition from a high-velocity lid to a low-velocity zone, based on a basic shear velocity structure. The $L A B$ can also be related to a change in anisotropy, as the process of lattice-preferred orientation of anisotropic crystals indicates the recording of the previous or current mantle flow. Thus, the inversion of only surface wave dispersion [Plomerova et al., 2002] or joint surface waves and SKS splitting measurements [Yuan et al., 2011] give access to depth variations of radial anisotropy, amplitude, and orientation of azimuthal anisotropy, where the SKS splitting data are used to complete the information from the surface wave dispersion on azimuthal anisotropy at depth.

Therefore, there is still controversy relating to the concept of the LAB below continental roots and oceanic regions. We first focus our search for the $L A B$ on the oceanic part of our global three-dimensional anisotropic model which has a more simple structure. The 3-D model includes the vertically polarized shear velocity, the radial anisotropy, and the azimuthal anisotropy. These parameters produce different estimates of the $L A B$ and geodynamic interpretation at a global scale can be carried out.

\section{Data Set}

The data set is composed of compiled Rayleigh and Love wave group and phase velocities. A very large amount of these data was collected from different groups. These include phase velocity dispersion data of the fundamental mode of the Love and Rayleigh waves from Harvard [Ekström et al., 1997] using a phase-matched filtering method, from IPGP [Beucler et al., 2003; Beucler and Montagner, 2006] using the roller coaster algorithm, and from Utrecht [Visser et al., 2008] using the model space approach. These also include group velocity dispersion data of the fundamental mode of the Love and Rayleigh waves from the University of Colorado [Ritzwoller and Levshin, 1998], using a frequency-time analysis. The complete data set initially contained more than 300,000 independent surface wave dispersion measurements (Table 1) provided by stations of permanent and temporary networks. These are based on data processing of the global scale distribution of seismic events over the past 20 years. Given that Rayleigh waves are mainly sensitive to the SV wave velocity, while Love waves are mainly sensitive to the $S H$ wave velocity, we can invert for a radial anisotropic structure. Group velocity measurements extend to shorter periods than phase velocity measurements (down to periods of $16 \mathrm{~s}$ ) and provide additional information on shallow layer effects and the crust-mantle structure.

One primary difficulty in this compilation comes from the heterogeneity of the sources and the processing techniques for phase velocity dispersion data. The different data sets include measured phase velocities and error bars that can be incompatible for the same paths, due to different data processing and measurement techniques. In a first step, the common paths between the different data sets (i.e., same event, same station) were compared. This comparison of these common paths shows important variations between the data sets. For common paths, the errors in the Harvard data set are almost systematically smaller than the errors in the Utrecht data set. In a second step, the merging of the data sets was performed by applying a global weighting coefficient on the data errors for each separate data set. The weighting coefficients were determined to minimize the a posteriori errors on the regionalization of the merged data sets. We used a systematic search of the different combinations and found the best weighting coefficients: $\sim 1.1$ for the IPGP data set, $\sim 1.6$ for the Utrecht data set, and $\sim 2.1$ for the Harvard data set. 


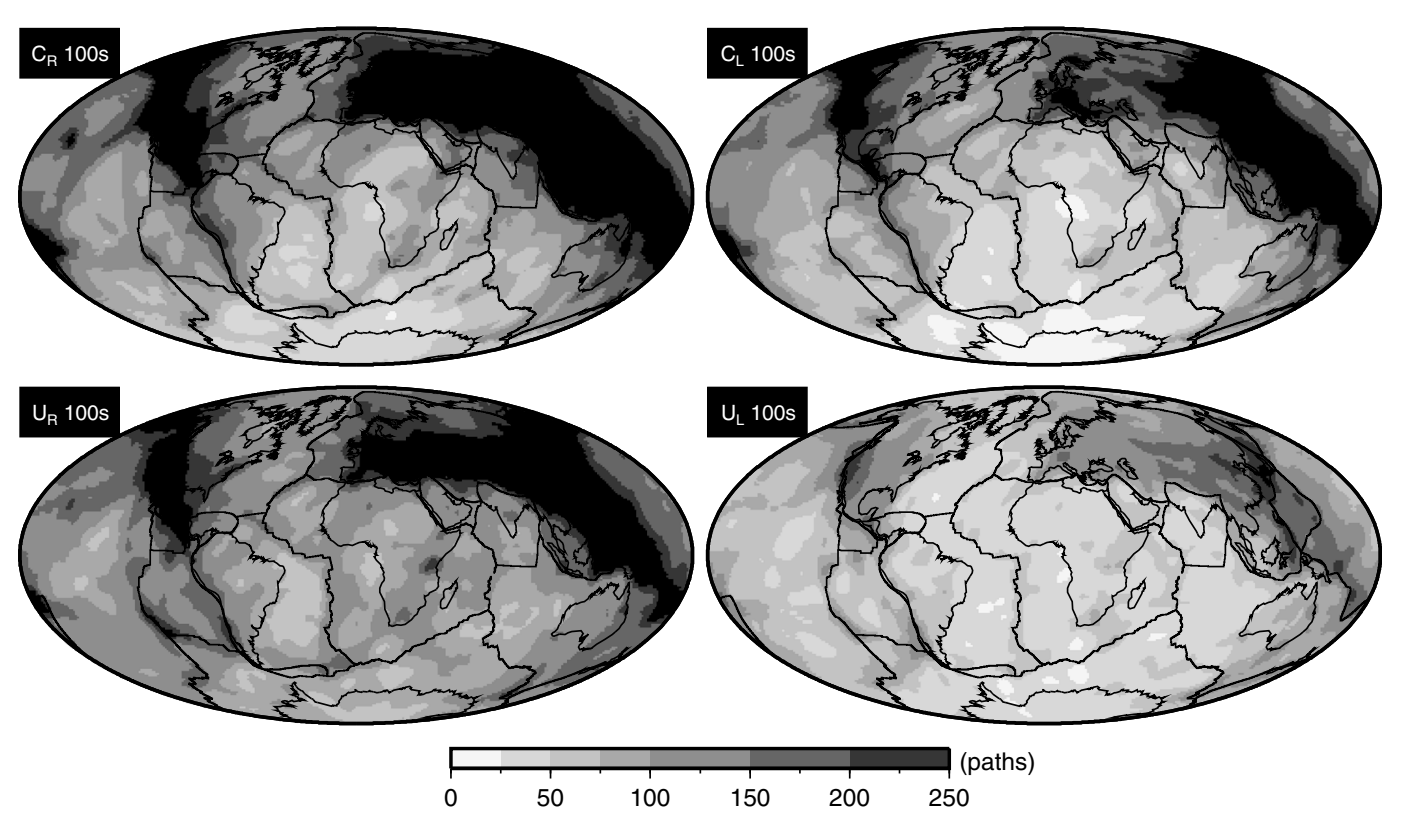

Figure 1. Path density coverage. Color scale indicates number of paths per unit area $\left(2^{\circ} \times 2^{\circ}\right.$ cell at the equator), cells are saturated at 250 paths. Maps for Rayleigh wave phase velocity $\left(C_{R}\right)$, Love wave phase velocity $\left(C_{L}\right)$, Rayleigh wave group velocity $\left(U_{R}\right)$, and Love wave group velocity $\left(U_{L}\right)$. All maps are at a period of $100 \mathrm{~s}$.

The data coverage obtained shows strong heterogeneities, according to the global distribution of stations and sources (Figure 1). The Southern Hemisphere has a lack of path density in comparison with the Northern Hemisphere, and especially in Antarctica ( 20 paths per $2^{\circ} \times 2^{\circ}$ cell for the Love phase velocity at $100 \mathrm{~s}$ ), and the south of the Atlantic and Indian Oceans ( $\sim 40$ paths per cell for Love group velocity at $100 \mathrm{~s})$. Instead, the North American continent and Eurasia show very dense path coverage (more than 1000 paths for the Rayleigh phase velocity). The global azimuthal coverage is satisfying at the global scale (Figure 2). However, we note some weakness in the almost North-South direction in the south of the Atlantic Ocean for the Love phase velocity.

\section{Phase Velocity and Group Velocity Maps}

The relationship between the seismic parameters describing the Earth's structure and the surface wave dispersion is nonlinear. There are many different methods to invert for a 3-D model, and we focused on only two techniques. The first, one-step, technique consists of direct waveform fitting, where the path associated kernels are calculated and relate the surface wave phase velocity data to the seismic parameters [Woodhouse and Dziewonski, 1984]. The second, two-step, technique [Nataf et al., 1986] consists of the estimation of 2-D dispersion maps for each period (which is a nearly linear problem) and thus the nonlinear inversion at depth of each local period dispersion curve with respect to a local 1-D model of seismic parameters.

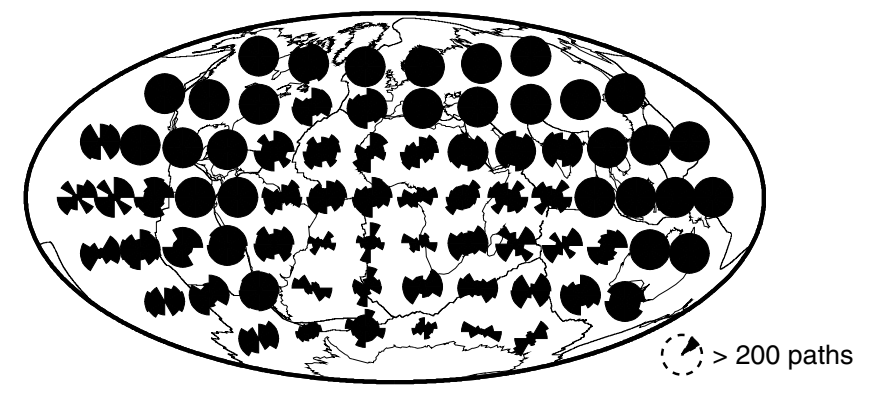

Figure 2. Path azimuthal coverage for Love wave phase velocity at a period of $100 \mathrm{~s}$. Length of slices indicates the number of paths per azimuth range $\left(30^{\circ}\right)$ per unit area $\left(10^{\circ} \times 10^{\circ}\right.$ cell at the equator), and the vectors are saturated at 200 paths. 
The prediction of maps of surface wave velocities for each wave type (phase velocity for Rayleigh and Love waves, and group velocity for Rayleigh and Love waves) and each period is performed by using the continuous regionalization algorithm. This technique solves the least square inverse problem based on the formalism of Tarantola and Valette [1982]. This was applied to surface waves by Montagner [1986] and was optimized especially for large amounts of data by Debayle and Sambridge [2004].

Following the geometrical ray approximation, the slowness along the great circle path can be expressed as

$$
\frac{1}{v_{i}(T)}=\frac{1}{\Delta} \int_{i} \frac{1}{v(\theta, \phi, T)} \mathrm{ds}
$$

where $v_{i}$ is the velocity measurement (either phase velocity or group velocity of Rayleigh or Love waves) for the $i^{\text {th }}$ path at period $T, \Delta$ is the epicentral distance between the earthquake and the receiver, $v$ is the local velocity at the geographic point of colatitude and longitude $(\theta, \phi)$. To complete the formulation of the forward problem, the first order dependence of the local surface wave velocity $v$ on the anisotropy can be expressed as a Fourier series expansion of azimuth $\psi$ up to degree 4 [Smith and Dahlen, 1973, 1975],

$$
\begin{gathered}
v(\psi, T)=v_{0}(T)\left[1+\alpha_{1}(T) \cos 2 \psi+\alpha_{2}(T) \sin 2 \psi\right. \\
\left.\alpha_{3}(T) \cos 4 \psi+\alpha_{4}(T) \sin 4 \psi\right],
\end{gathered}
$$

where $\psi$ is the azimuth, $v_{0}$ is the isotropic term, and $\alpha_{1}, \alpha_{2}, \alpha_{3}$, and $\alpha_{4}$ are the anisotropic coefficients of the azimuthal terms.

This least squares inversion formalism involves a Gaussian a priori covariance matrix that is based on a correlation length that controls the lateral resolution of the 2-D inverted map. The inversion scheme formulation of Debayle and Sambridge [2004] allows the use of massive data sets but does not allow the calculation of the a posteriori covariance matrix, which is computationally too expensive.

In this study, we use cluster analysis to match the upper limit of the path number that can be computed by the algorithm. The paths that have quasi similar source and receiver coordinates are gathered to produce a single path with an average value and an error defined by the standard deviation. In practice, we use clustering in $1^{\circ} \times 1^{\circ}$ cells for at least 20 similar paths. Additionally, for a cell including $n$ paths, the error is replaced by the RMS of the $n$ velocities. For each velocity map, two inversions are processed: The first is based on the starting velocity that is inferred from the preliminary reference Earth model (PREM) [Dziewonski and Anderson, 1981], the second is based on the global average of the first map, in order to reduce the dependence on the starting model. To estimate the correlation length, we find that in the data set an isotropic part correlation length $L_{i}=400 \mathrm{~km}$ and an anisotropic part correlation length $L_{a}=800 \mathrm{~km}$ provide an accurate compromise between improved resolution and a posteriori uncertainties. These values of correlation length are also necessary to be in the framework of the geometric optics and thus to avoid strong diffraction effects. A statistical error is estimated by inverting 10 random samplings of $80 \%$ of the data set, and the errors are thus obtained by the calculation of the standard deviation of the stacked samples of the complete catalog. The compatibility of the merged phase velocity data set is assessed by comparison with individual data sets and it reflects the weighting of the data set relative errors.

As an example of dispersion maps, we can see the major regional tectonic structures on the 100s phase velocity map (with a maximum sensitivity at $\sim 130 \mathrm{~km}$ for the Rayleigh waves, and just beneath the crust for the Love waves), as mainly high-velocity cratons and low-velocity ocean ridges (Figure 3). In Figure 4, we can also see the strong sensitivity to the crust of the group velocity at short periods, where the ocean-continent distribution is predominant. The smooth anisotropic direction signal can be interpreted as a record of the flow direction beneath the oceans. These very general features are similar and coherent with other previous studies of dispersion maps [see Trampert and Woodhouse, 2003; Beucler and Montagner, 2006; Ekström, 2011].

\section{Crustal Model}

Surface waves are strongly sensitive to shallow layers [see Montagner and Tanimoto, 1991; Marone and Romanowicz, 2007]. To avoid the mantle structure being biased by the crust, it is necessary to carefully take account of the strong lateral variations of the crustal structure. As Love waves have a shallower sensitivity 


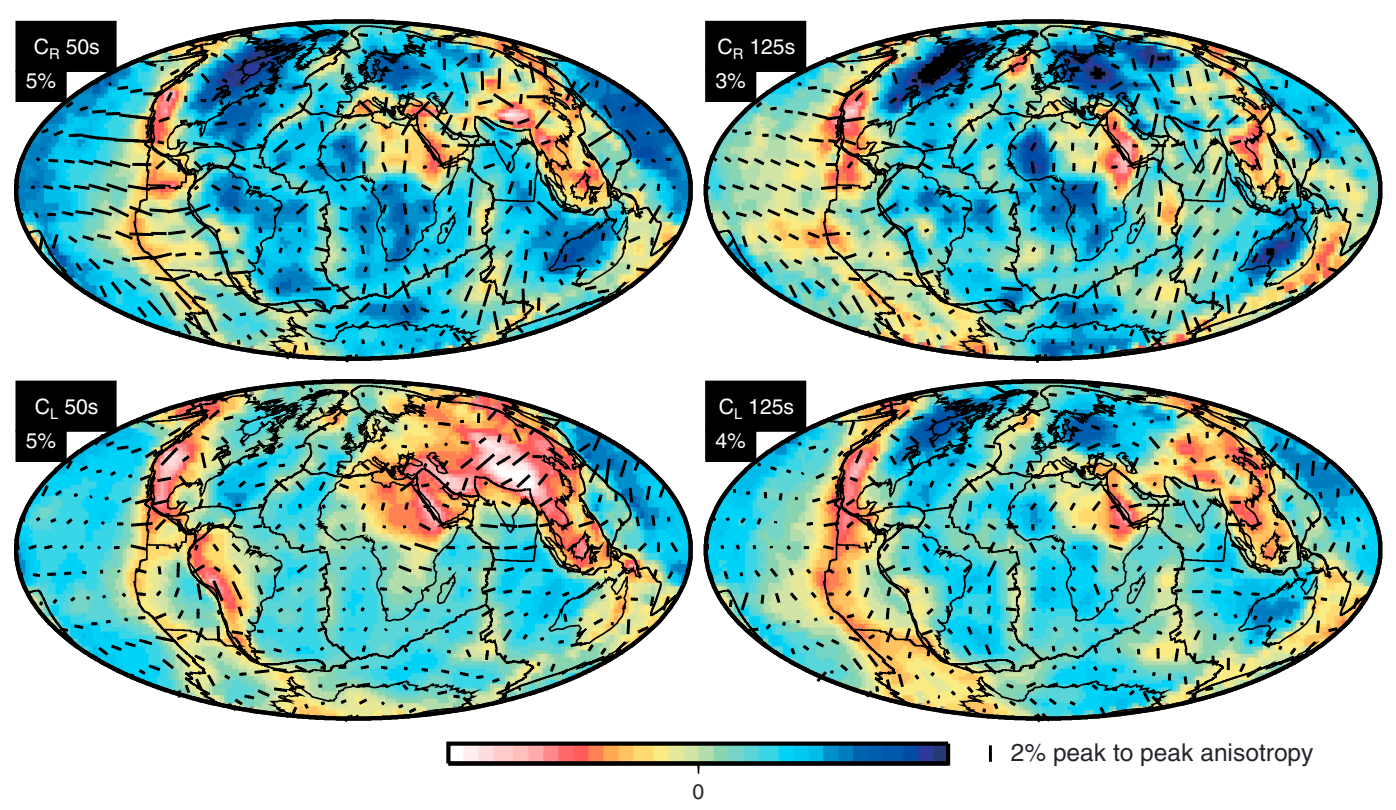

Figure 3. Two-dimensional regionalization. Color scale indicates the perturbation of isotropic velocity with respect to the PREM (the maximum range of the scales are indicated beneath each subtitle). The amplitude and orientation of vectors indicate the fast axis of $2 \psi$ azimuthal anisotropy. Maps for Rayleigh wave phase velocity $\left(C_{R}\right)$ at periods of $50 \mathrm{~s}$ and $125 \mathrm{~s}$, and Love wave phase velocity $\left(C_{L}\right)$ at periods of $50 \mathrm{~s}$ and $125 \mathrm{~s}$.

than Rayleigh waves at a given period, a wrong crustal correction can lead to nonphysical radial anisotropy at depth [Ferreira et al., 2010].

In the present study, we jointly invert the phase and group velocity data for Rayleigh and Love waves in selected short period bands for a crustal model. The different sensitivities of the different types of data provide better constraints on the crustal structure and reduce the mapping of mantle heterogeneities in the crust.
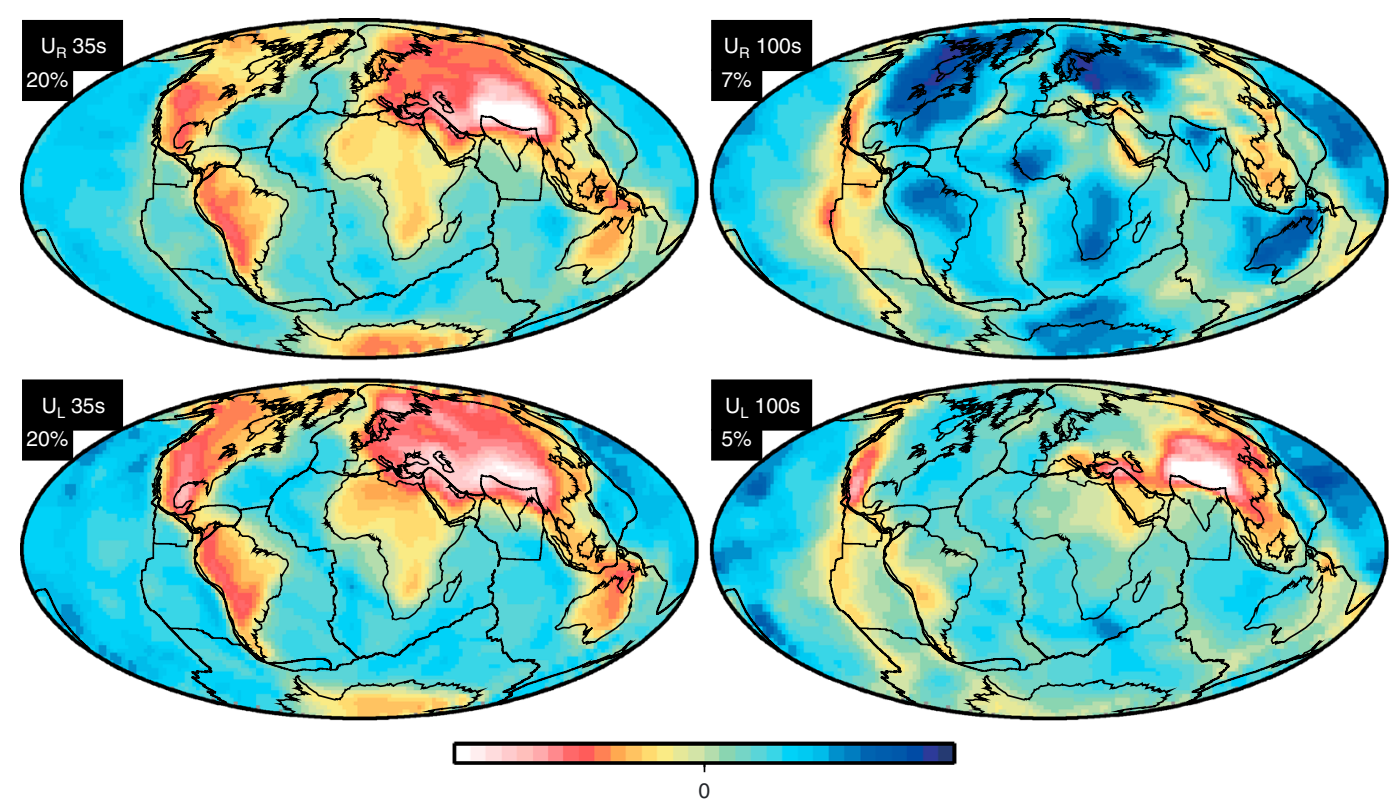

Figure 4. Two-dimensional regionalization. Color scale indicates the perturbation of isotropic velocity with respect to the PREM (the maximum range of the scales are indicated beneath each subtitle). Maps for Rayleigh wave group velocity $\left(U_{R}\right)$ at periods of $35 \mathrm{~s}$ and $100 \mathrm{~s}$, and Love wave group velocity $\left(U_{L}\right)$ at periods of $35 \mathrm{~s}$ and $100 \mathrm{~s}$. 
There are several approaches to correct for the effects of the crust on dispersion velocities. The first consists of selecting one of the available a priori crustal models and to compute corrections applied to data or to define this model as a fixed part for the inversion. The second approach consists of a joint inversion of crust and mantle structures. In this study, we choose a hybrid method: we perform a Monte Carlo inversion only for the crustal structure based on an a priori model, and we try to fit the shorter period range of data sensitive to the crust. This technique provides a more accurate crustal model that is compatible with the data and avoids mantle contamination by the crustal heterogeneities better than the direct inversion.

The initial crustal model contains the $P$ wave velocity, $S$ wave velocity, density, and shear quality factor. It is based on the crustal model CRUST 2.0 [Bassin et al., 2000] (with the crustal quality factor of the PREM model crust), which includes topography, water bathymetry, sedimentary layers, and three crustal layers. We use the isotropic PREM model below the $220 \mathrm{~km}$ discontinuity. Between the Moho and the $220 \mathrm{~km}$ discontinuity, we perform a linear average to relate the CRUST 2.0 uppermost mantle values and the PREM values at the $220 \mathrm{~km}$ discontinuity.

Due to their respective sensitivity, we use Rayleigh wave phase velocity $C_{R}$ in the period range of $35 \mathrm{~s}$ to $40 \mathrm{~s}$, Love wave phase velocity $C_{L}$ in the period range $35 \mathrm{~s}$ to $50 \mathrm{~s}$, Rayleigh wave group velocity $U_{R}$ in the period range $20 \mathrm{~s}$ to $40 \mathrm{~s}$, and Love wave group velocity $U_{L}$ in the period range $20 \mathrm{~s}$ to $50 \mathrm{~s}$.

Model space sampling methods, such as for Monte Carlo, Metropolis, or simulated annealing need a small number of parameters and a fast routine to solve the forward problem, to explore the model space adequately. A simulated annealing inversion is applied, which uses random sampling of the model space (in an analogy with the annealing of solids) [Kirkpatrick et al., 1983]. Each model generation is constructed as a random perturbation of a previous model. The probability of the generated model to be accepted slowly reduces as the number of iterations increases. This makes possible a more global walk before converging onto a local solution that is adapted to the crust and to the multiple trade-offs between the depths and velocities in each layer. The cost function $s_{k}$ at each iteration $k$ is computed as

$$
s_{k}=\sum_{i} \frac{\left(v_{i}^{k}-v_{i}\right)^{2}}{\sigma_{i}^{2}}, \quad v=\left[C_{R} C_{L} U_{R} U_{L}\right]^{T},
$$

where $v_{i}$ is the velocity of rank $i$ in the data vector (either Rayleigh or Love wave, either phase or group velocity, and for a given period), $\sigma_{i}$ is the associated uncertainty, $v_{i}^{k}$ is the corresponding velocity computed for the $k^{\text {th }}$ generated model. The probability of the $k^{\text {th }}$ model to be accepted is

$$
\left\{\begin{array}{l}
T_{k}=a\left(1-\frac{k}{n}\right) \\
P_{k}=\exp \left(\frac{-\Delta s_{k}}{T_{k}}\right),
\end{array}\right.
$$

where $T_{k}$ is the annealing temperature, which decreases as the number of iterations increases ( $n$ is the maximum number of iterations), and $a$ is a parameter that scales the amplitude of the random walk. $P_{k}$ is the probability for the model $k$ to be accepted, and $\Delta s_{k}$ is the variation of fit between the previously accepted model and the $k$ model.

The fast routine that is necessary to realize the high number of iterations of the SA scheme is a plane wave computation of surface wave dispersion in a semiinfinite half-space [Herrmann, 1987]. This technique is compatible with the normal mode computation [Woodhouse, 1998] for this depth and period range. The parameterization of the inversion is chosen so as to get the smallest possible number of parameters. The water layer and the sedimentary layers are fixed in the inversion scheme which perturbs only the three crustal layers. As the surface waves are mainly sensitive to the $S$ wave velocity, we invert only for this parameter by defining perturbations of the $P$ wave velocity and density as logarithmic relation to the $S$ wave perturbation $d \ln V_{p} / d \ln V_{s}=0.5$ and $d \ln \rho / d \ln V_{s}=0.33$. No radial anisotropy is introduced in the crust.

The inversion is performed at each geographic point of the 10,468 points of the global grid that describes the regionalized maps. In Figure 5 the best fit Moho depth distribution is shown. The inverted model usually displays deeper Moho depths than the CRUST 2.0 model, and the variation in the oceanic regions is very small due to the accurate starting model and smaller parameter space. However, cratonic parts, such as Western Australia, northern America, western and southern Africa have a shallower Moho than CRUST 2.0. Our results are consistent over the large scale with other global studies based on surface wave data [Meier and Curtis, 2007] or other European studies [Tesauro et al., 2008]. 


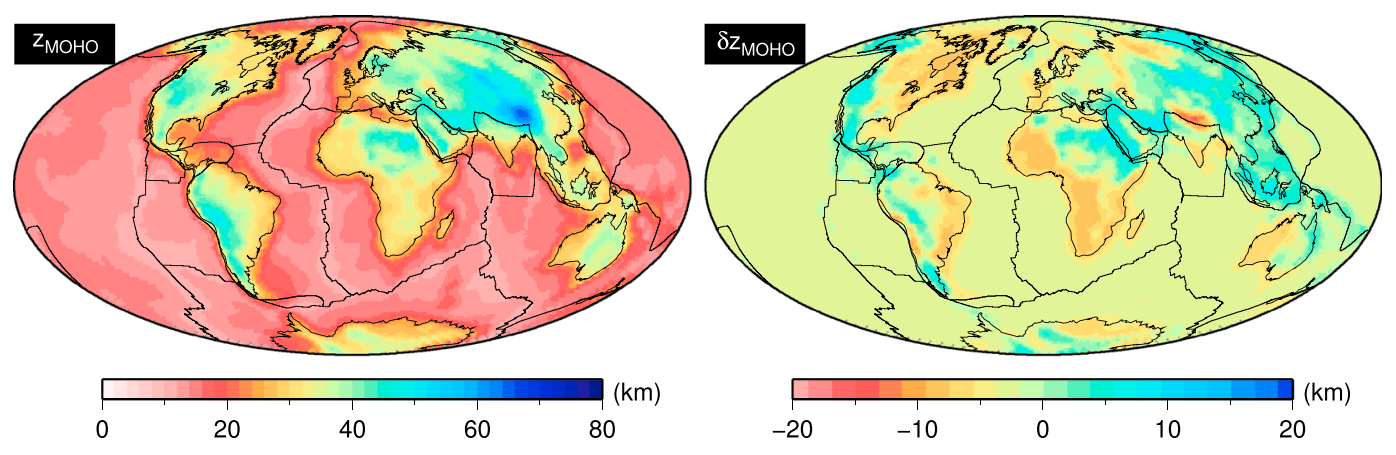

Figure 5. Best solution for the Moho depth for the crustal Monte Carlo inversion. Maps for the absolute depth of the best fit Moho and for the difference $(\mathrm{km})$ between the best fit Moho and the CRUST 2.0 Moho from the starting model.

\section{Depth Inversion by First-Order Perturbation Theory}

To obtain a 3-D model of the upper mantle, we perform an inversion at depth of the dispersion velocities for a complete anisotropic structure.

From a general point of view, surface waves are sensitive to 13 parameters among 21 of the elastic tensor, which corresponds to a monoclinic lattice system (one plane of symmetry). This geometry makes it possible to take azimuthal anisotropy into account. The first five parameters are $A, C, F, L$, and $N$, and these can be associated with the $P H$ wave and $P V$ wave velocities, the $\eta$ anisotropy, and the SV wave and SH wave velocities, respectively. The other eight parameters represent the azimuthal variations of the five parameters, except $C$ : The $2 \psi$ variations for $A$ by $B_{c}$ and $B_{s}$, for $L$ by $G_{c}$ and $G_{s}$, for $F$ by $H_{c}$ and $H_{s}$, and the $4 \psi$ variations for $N$ by $E_{c}$ and $E_{s}$.

The starting model contains $A, C, F, L, N, Q_{K}$ and $Q_{\mu}$. It is based on the inverted crustal model (for each point of the 2-D grid) fitting of the short period range of the data set, with $A=C, L=N$, and based on the PREM model $F, Q_{\kappa}$ and $Q_{\mu}$. The upper mantle structure (down to $410 \mathrm{~km}$ ) is a modified anisotropic PREM model where the radial anisotropy $(\xi-1)$ is reduced from the original $10 \%$ to $4 \%$, and the $220 \mathrm{~km}$ discontinuity is smoothed by using a $40 \mathrm{~km}$ Gaussian filter.

Therefore, in the period range $35 \mathrm{~s}$ to $300 \mathrm{~s}$, we use isotropic and anisotropic coefficients ( $2 \psi$ and $4 \psi$ ) of the phase velocity for the Rayleigh waves, and in the period range $35 \mathrm{~s}$ to $175 \mathrm{~s}$, we use isotropic and anisotropic coefficients $(2 \psi$ and $4 \psi$ ) of the phase velocity for the Love waves.

Assuming weak anisotropy and small heterogeneities, we can express the forward problem following the first order perturbation formalism for Rayleigh phase velocity perturbation at a period $T$ as

$$
\begin{aligned}
\delta c_{R}(T)=\int_{0}^{a}\left[\frac{\partial c_{R}}{\partial A}(T)(\delta A\right. & \left.+B_{c} \cos 2 \psi+B_{s} \sin 2 \psi+E_{c} \cos 4 \psi+E_{s} \sin 4 \psi\right) \\
+ & \frac{\partial c_{R}}{\partial C}(T) \delta C+\frac{\partial c_{R}}{\partial F}(T)\left(\delta F+H_{c} \cos 2 \psi+H_{s} \sin 2 \psi\right) \\
& \left.+\frac{\partial c_{R}}{\partial L}(T)\left(\delta L+G_{c} \cos 2 \psi+G_{s} \sin 2 \psi\right)\right] \frac{\mathrm{d} z}{\Delta h},
\end{aligned}
$$

where $a$ is the Earth radius and $\Delta h$ is the normalizing thickness for the kernels.

For the Love phase velocity perturbation

$$
\begin{aligned}
\delta c_{L}(T)= & \int_{0}^{a}\left[\frac{\partial c_{L}}{\partial L}(T)\left(\delta L+G_{c} \cos 2 \psi+G_{s} \sin 2 \psi\right)\right. \\
& \left.\frac{\partial c_{L}}{\partial N}(T)\left(\delta N+E_{c} \cos 4 \psi+E_{s} \sin 4 \psi\right)\right] \frac{\mathrm{d} z}{\Delta h}
\end{aligned}
$$

The kernel formulation is based on Takeuchi and Saito [1972] for the transverse isotropic medium with vertical symmetry axis, and it allows the derivation of the anisotropic ones [Montagner and Nataf, 1986].

The inversion algorithm [Tarantola and Valette, 1982] makes the control of the vertical resolution possible by using a Gaussian a posteriori covariance matrix for the parameter space that is characterized by an a priori error on the parameter and a correlation length. This correlation length increases with depth from $20 \mathrm{~km}$ to 

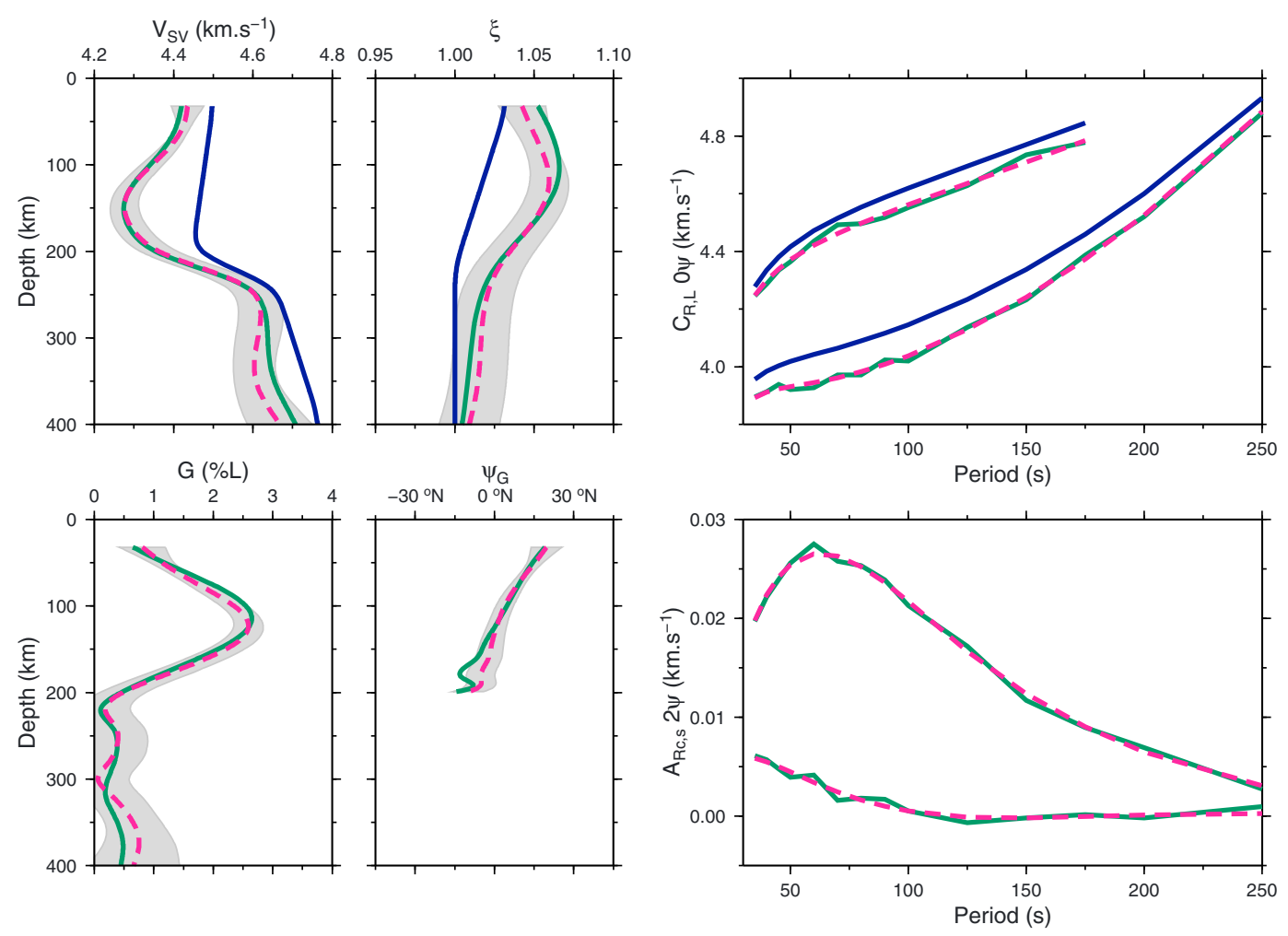

Figure 6. Synthetic test of the resolutions: example of an oceanic model. (left) Profiles of the $V_{\mathrm{sv}}, \boldsymbol{\xi}$, and strength $G$ parameters, and orientation of the fast axis $\psi_{G}$ of the azimuthal anisotropy, with the starting model (blue), the perturbed model (green), and the inverted model (red) with uncertainties (gray). The dispersion curves associated with the different models are presented, with the (top right) Rayleigh wave and Love wave phase velocities and the (bottom right) $2 \psi$ azimuthal coefficients of the Rayleigh wave phase velocity. The orientation of the azimuthal anisotropy $\psi_{G}$ is not shown for weak values of anisotropy strength $G$.

a maximum of $50 \mathrm{~km}$ at the bottom of the upper mantle, which corresponds to the distribution of the independent quantity of the surface wave information. The computational cost is dominated by the calculation of the kernels at each point of the grid, which is performed through the modal solution with a modified version (Capdeville, personal communication, 2014) of modular in-core nonlinear optimization system (MINOS) code [Woodhouse, 1998]. In addition to the correlation length and a priori errors, the a posteriori covariance matrix for the parameter space is also used to impose a priori correlations between the whole set of parameters. These correlations are inferred from petrological constraints to reduce the number of independent model parameters [see Montagner and Anderson, 1989].

The inversion is performed individually for each geographic point of the global grid. The sensitivity kernels of the Rayleigh waves and the respective Love waves show that parameters $L, G_{c^{\prime}}$ and $G_{s^{\prime}}$ and ,respectively, $N$, $E_{c}$, and $E_{s}$, are predominant over the others. The resolution of these parameters is estimated through a set of synthetic tests with various amplitudes of perturbation at different depths, which demonstrates that $L, N, G_{c}$, and $G_{s}$ are resolved (see Figure 6). These parameters will be described as the $S V$ wave velocity $V_{S V}=\sqrt{L / \rho}$, the radial anisotropy $\xi=N / L$, the strength of the $V_{s}$ azimuthal anisotropy $G=\sqrt{G_{c}^{2}+G_{s}^{2}}$ and the fast axis orientation $\psi_{G}=1 / 2 \arctan \left(G_{c}, G_{s}\right)$.

Classical regional scale tectonic features, such as the cratonic regions associated with high-velocity or oceanic regions, and ridges associated with low velocities at $125 \mathrm{~km}$ depth, are retrieved in $V_{\text {sV }}$ depth maps (Figure 7). The borders of the subduction zone are well defined for Cascadia, Japan; e.g., on 75 km and $125 \mathrm{~km}$ maps. The fast axis direction of azimuthal anisotropy remains mainly coherent with the global plate motion for oceanic regions and has a more complicated pattern beneath the continental regions. The radial anisotropy maps (Figure 8) show strong anisotropy zones $\xi>1$ for oceanic regions, especially for the Pacific Ocean region, as reported in Montagner and Tanimoto [1991] and Ekström and Dziewonski [1998], and a more complicated geometry for continental regions. In this study, we present only the results for the oceanic lithosphere, whereby the results for the continents will be discussed in a future study. For all of the 


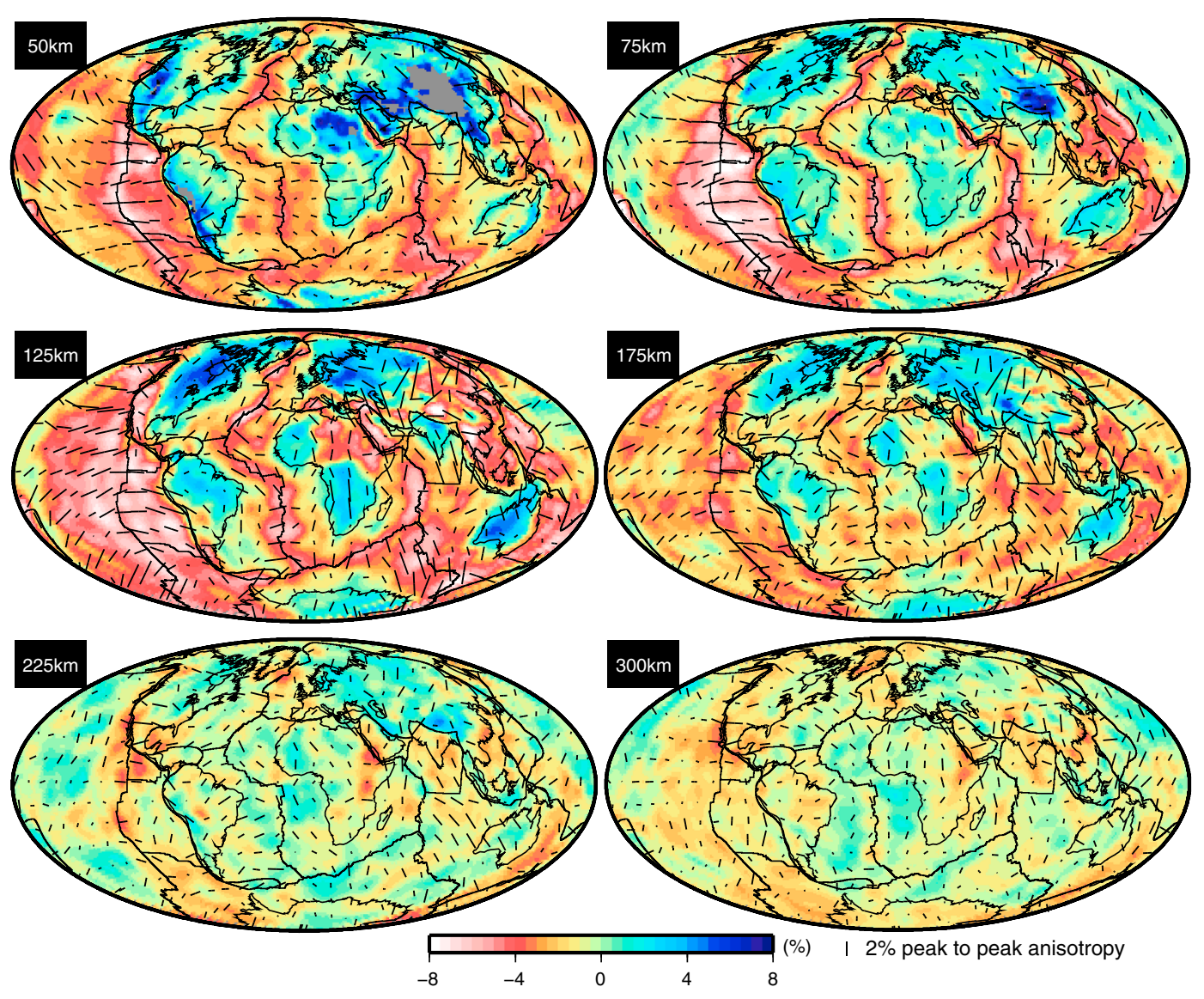

Figure 7. Depth maps of the $V_{\mathrm{SV}}$ parameter and $\psi_{\mathrm{G}}$ from the inversion at depth. Color scale indicates the perturbation of $V_{\mathrm{SV}}$ with respect to the pseudo-PREM reference. The amplitude and orientation of the vectors indicate the fast axis of $G$ azimuthal anisotropy.

parameters, the 3-D inversion at depth mainly reproduces the minimum lateral wavelength imposed in the 2-D regionalization step.

\section{LAB Proxies}

The seismic $L A B$ depth can be inferred from the inverted parameters of the 3-D model by defining proxies (Figure 9) [see Van der Lee, 2002; Plomerova et al., 2002; Yuan et al., 2011]. The LAB can be related to the $V_{\text {sv }}$ parameter as the top of the low-velocity zone. For our inverted 3-D model, the maximum of the negative gradient of the SV wave velocity is computed and considered as the LAB. This represents the transition between the high-velocity lithosphere and the low-velocity asthenosphere. Beneath oceanic regions, the profile of radial anisotropy shows a low $\xi$ for shallow depths and then a high $\xi$, before converging toward $\sim 1$. The maximum of the radial anisotropy $\xi$ can be interpreted as the maximum deformation, and the LAB can be located at the maximum or just above the maximum, depending on the mechanical response of the asthenosphere. As we focus on the oceanic regions, we choose to pick the LAB above the maximum of $\xi$; i.e., at the maximum of the positive gradient $\frac{\partial \xi}{\partial z}$.

As in the case for the radial anisotropy, the strength of the azimuthal anisotropy $G$ can be used to define the $L A B$ depth, although the depth distribution obtained is scattered and does not provide a coherent pattern. Thus, we use the orientation of the fast axis of azimuthal anisotropy $\psi_{G}$. The change in the correlation between $\psi_{G}$ and the direction of the plate motion (no-net-rotation NUVEL-1 model) at depth can indicate a change in the rheology. It is assumed that $\psi_{G}$ reflects the orientation of the present-day mantle flow beneath the lithosphere, which is similar to the plate motion direction. When $\psi_{G}$ is not correlated with plate motion, it reflects the frozen-in anisotropy in the lithosphere. Thus, the top of the correlated orientation layer might define the LAB. In some cases the mantle flow did not change from the formation of the 

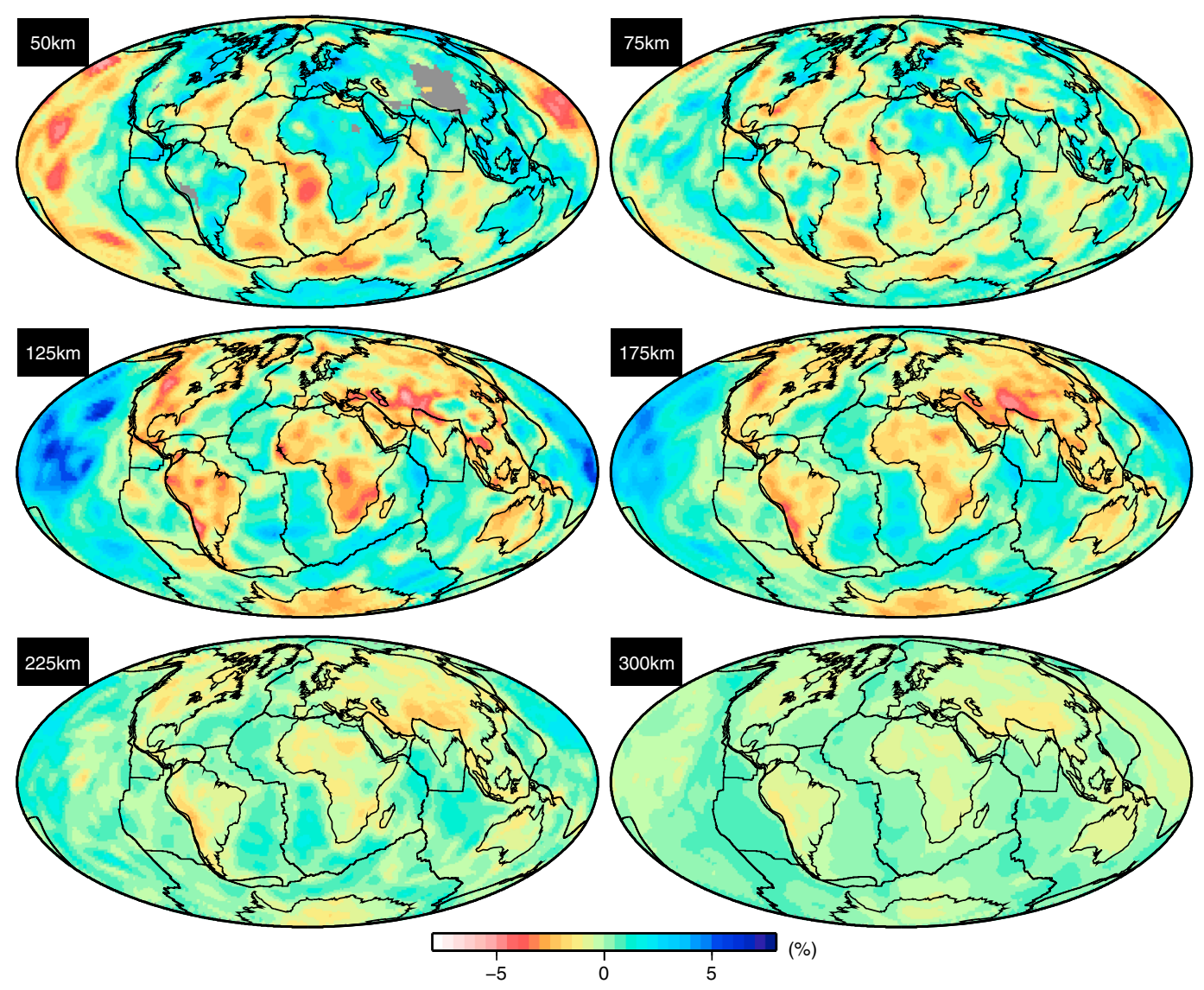

Figure 8. Depth maps of the $\xi$ parameter from the inversion at depth. Color scale indicates the perturbation of $\xi-\xi_{R}$, with respect to the average reference $\xi_{R}$.
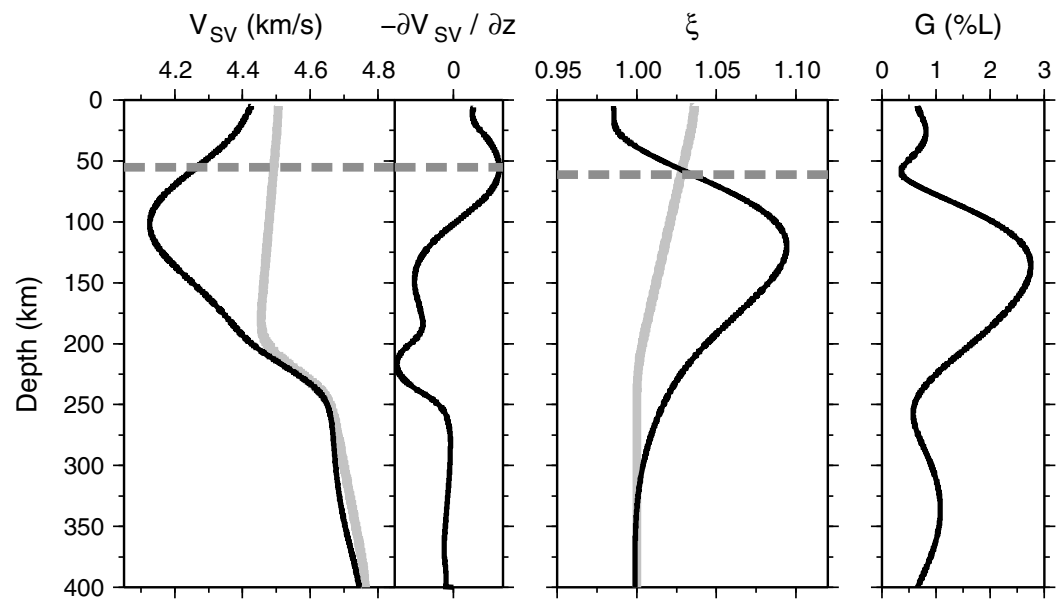

$\psi_{\mathrm{G}}$

$90^{\circ} \mathrm{N} 135^{\circ} \mathrm{N} 180^{\circ} \mathrm{N}$

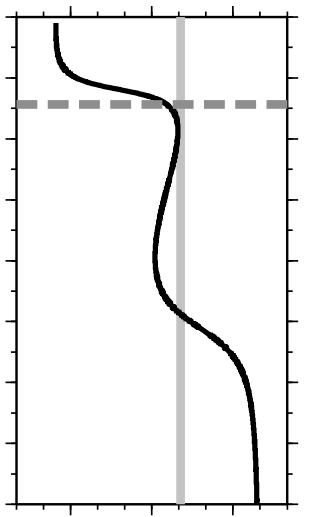

Figure 9. $L A B$ proxies for an oceanic point $\left(\lambda=35^{\circ} N, \phi=35.03^{\circ} \mathrm{W}\right)$. The profiles are shown for the shear velocity $\left(V_{\mathrm{sv}}\right)$, the shear velocity negative gradient $\left(-\partial V_{\mathrm{sv}} / \partial z\right)$, the radial anisotropy $(\xi)$, the amplitude of the azimuthal anisotropy $(G)$, and the orientation of the azimuthal anisotropy $\left(\psi_{G}\right)$ (black). The reference values of the starting model are in light gray, and the reference for $\psi_{G}$ is the corresponding direction of the plate motion from the no-net-rotation (NNR)-NUVEL-1 model. The LAB depths inferred from the different LAB proxies are in dashed gray: the depth to the maximum of the negative gradient for the shear velocity, the depth to the maximum of the positive gradient for the radial anisotropy, and the top of the correlated layer between the plate motion and the azimuthal fast axis for the orientation of the azimuthal anisotropy. 

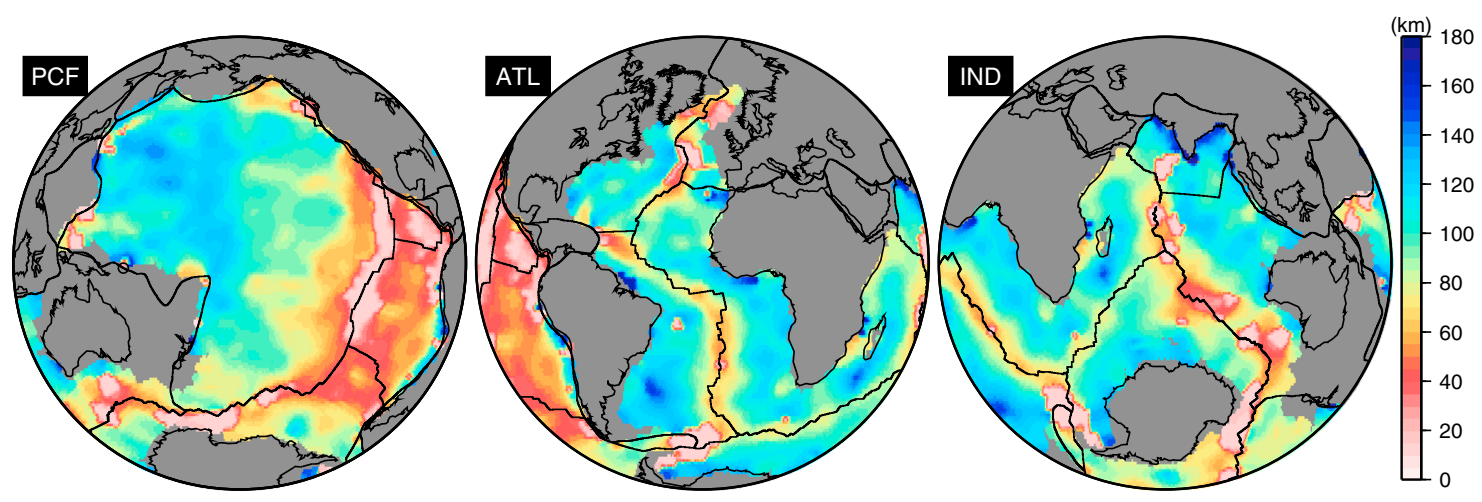

Figure 10. $L A B$ depth from the shear velocity $\left(V_{\mathrm{sv}}\right)$ proxy (maximum of the negative gradient). Color scale indicates the LAB depth ( $\mathrm{km}$ ) for the oceanic regions: Pacific (PCF), Atlantic (ATL), and Indian (IND) Oceans.

lithosphere up to now, and so $\psi_{G}$ cannot provide a coherent determination of the LAB depth. We consider the orientation of the azimuthal anisotropy proxy when the anisotropy strength is greater than $0.5 \%$.

For oceanic regions, the LAB derived from the vertically polarized shear velocity proxy (Figure 10) has shallow depth values beneath the ridges $(\sim 30 \mathrm{~km})$, and it increases as the age of the lithosphere increases. In old oceanic regions, the LAB depth is up to $\sim 120-130 \mathrm{~km}$. The LAB depth derived from the radial anisotropy $\xi$ (Figure 11) shows a faster increase with the age than the $V_{S V}$ proxy, before reaching a shallow subhorizontal pattern ( 70-80 km). The azimuthal anisotropy proxy for the LAB is computed only for the Pacific region (Figure 12), as a coherent pattern in the Atlantic and Indian regions was not found. The LAB depth inferred from the correlation of the orientation of azimuthal anisotropy and the direction of the plate motion is $\sim 50 \mathrm{~km}$ around the ridge, and increases down to $\sim 125 \mathrm{~km}$ in depth for old oceanic regions. However, the $\psi_{G}$ proxy just below the ridges is not well defined.

\section{Age Versus Depth Correlations}

Plotting the oceanic LAB depth with the age of the ocean floor allows the comparison of our results with the thermal cooling models of the oceanic lithosphere. These models are based on bathymetric and geodetic measurements, and they predict the evolution of the topography, heat flux, and plate thickness as functions of the age. The lithosphere is defined as the upper conductive thermal boundary layer of the mantle that is cooling from the top. There are two main types of thermal models: the infinite half space models [Parker and Oldenburg, 1973] and the plate models [Parsons and Sclater, 1977; Stein and Stein, 1992; Doin and Fleitout, 1996; McKenzie et al., 2005], where the lithosphere thickness can be determined for a given isotherm.

For each oceanic region, the sea floor age is derived from Müller et al. [1997]. We plot the age/depth variations for the different elastic parameter proxies and we compare these with the half space cooling (HSC)
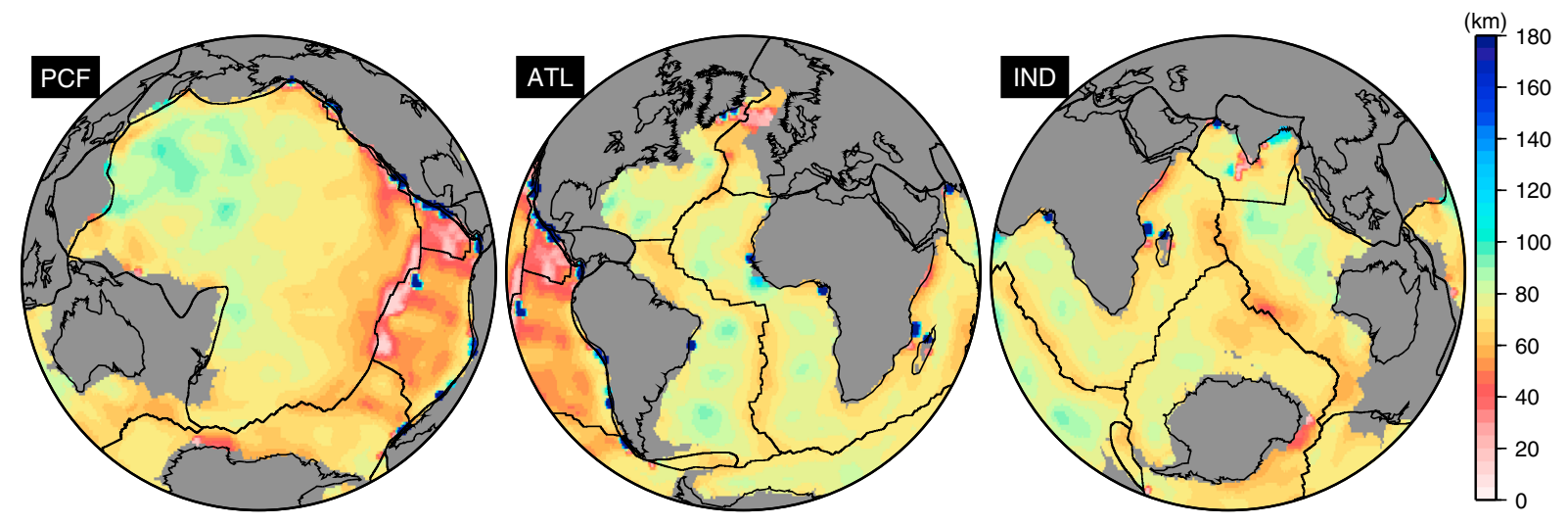

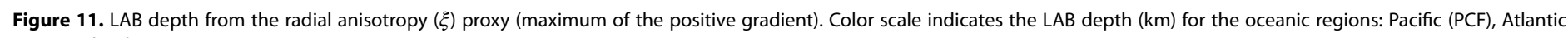
(ATL), and Indian (IND) Oceans. 

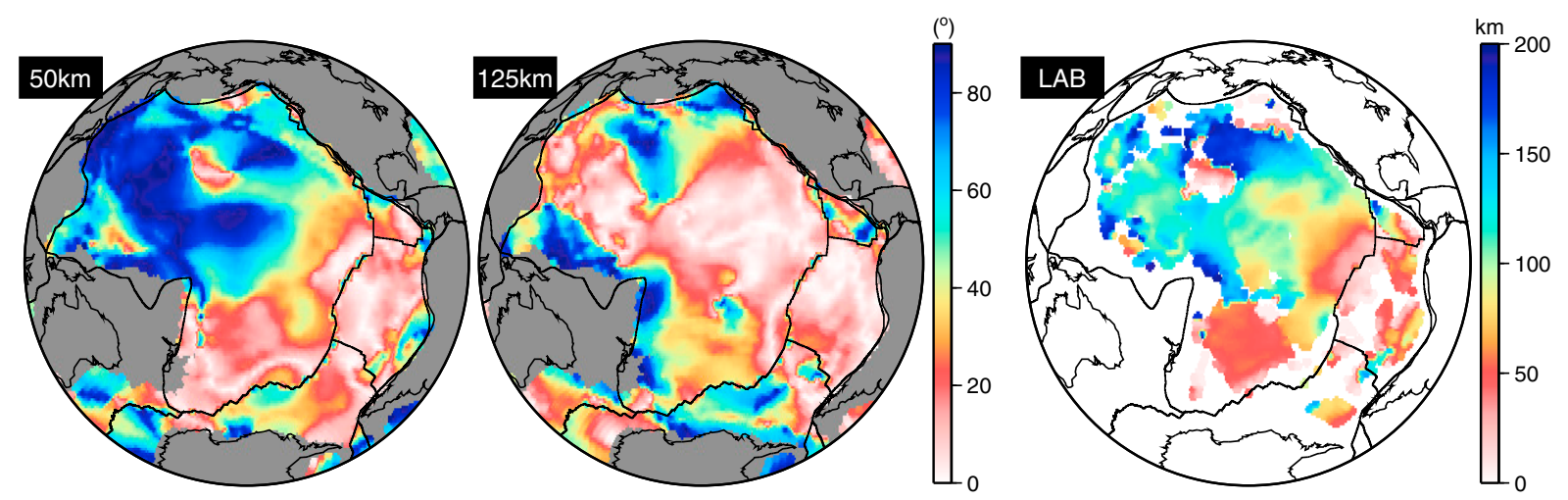

Figure 12. (left and middle) Depth maps of the difference between the orientation of the azimuthal anisotropy $\left(\psi_{G}\right)$ and the direction of the plate motion from the NNR-NUVEL-1 model for the Pacific Ocean at $50 \mathrm{~km}$ and $125 \mathrm{~km}$. Color scale indicates the angular difference $\left(^{\circ}\right)$. (right) LAB depth for the orientation of the azimuthal anisotropy proxy $\left(\psi_{G}\right)$ in the Pacific Ocean. Color scale indicates the LAB depth $(\mathrm{km})$. The incoherent points are rejected.

model and a more recent plate model, the McKenzie (MCK) model [McKenzie et al., 2005]. For all of the geographic points of each ocean grid, all of the LAB depths of the different proxies are associated with the corresponding age of the Pacific Ocean (Figure 13), the Atlantic Ocean (Figure 14), and the Indian Ocean (Figure 15). The age variation for the orientation of the azimuthal anisotropy $\psi_{G}$ proxy is only shown for the Pacific region, with a rejection of the incoherent points. This proxy shows the difference between the fossil

\section{Pacific Ocean}
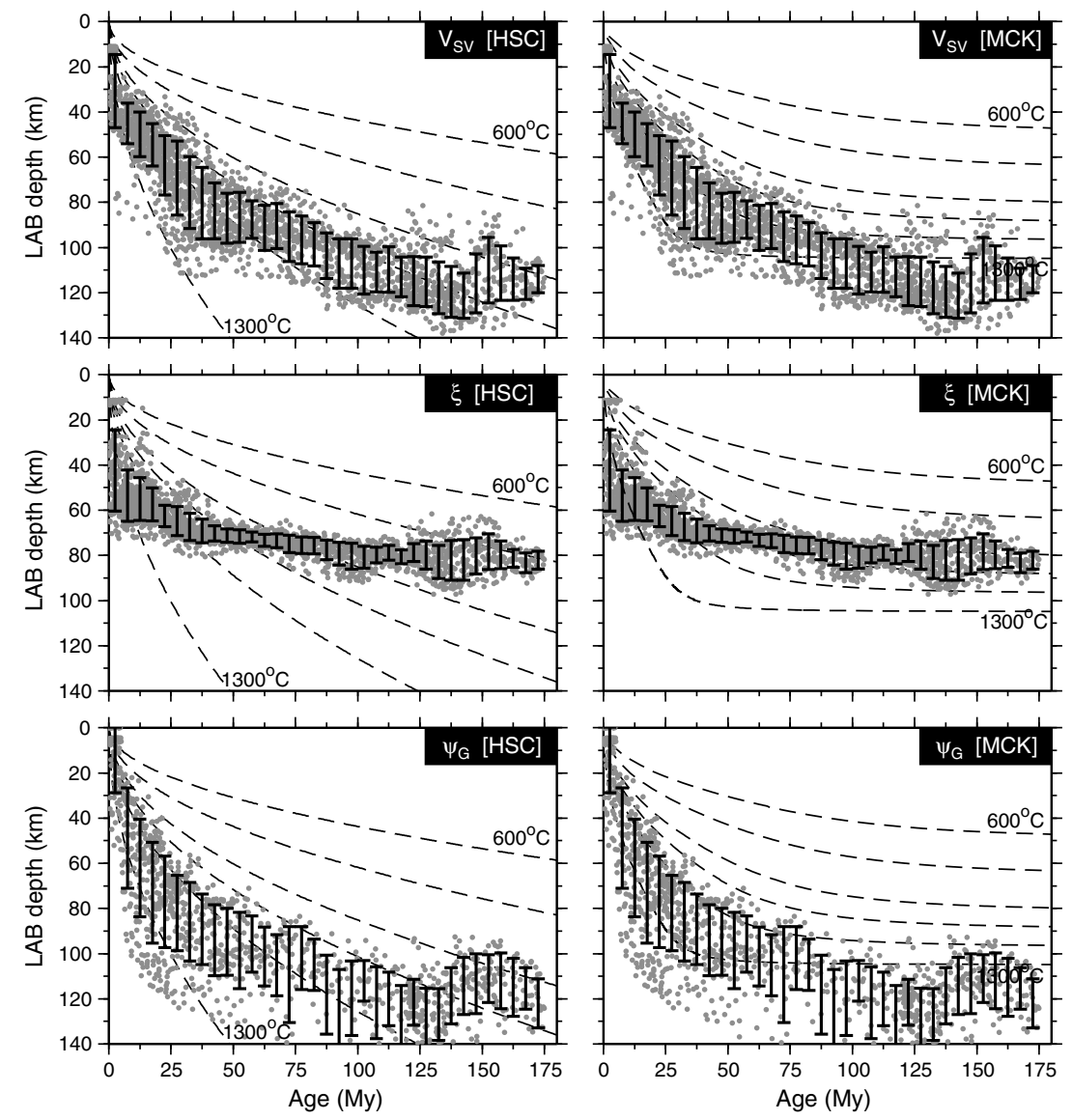

Figure 13. $L A B$ depth age variations for the Pacific Ocean floor. The diagrams represent the shear velocity $\left(V_{\mathrm{SV}}\right) L A B$ depth, the radial anisotropy $(\xi) \mathrm{LAB}$ depth, and the azimuthal anisotropy $\left(\psi_{G}\right) \mathrm{LAB}$ depth. The isotherms $600^{\circ} \mathrm{C}, 800^{\circ} \mathrm{C}, 1000^{\circ} \mathrm{C}, 1100^{\circ} \mathrm{C}, 1200^{\circ} \mathrm{C}$, and $1300^{\circ} \mathrm{C}$ (dashed gray) associated with the half space cooling model (HSC) and the McKenzie plate model (MCK) are also shown. The error bars are the standard deviations over the set of the age/depth points with a $5 \mathrm{Myr}$ age range. 


\section{Atlantic Ocean}

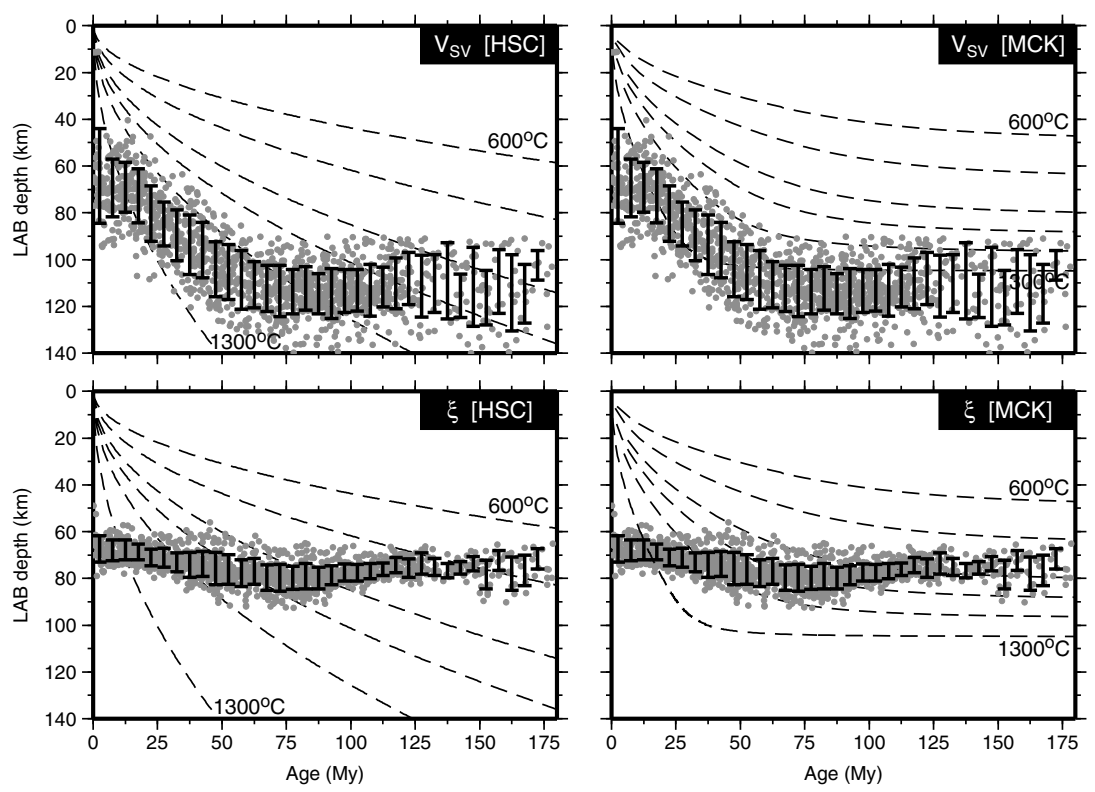

Figure 14. Same as Figure 13 but for the Atlantic Ocean.

anisotropy in the lithosphere and the present-day mantle flow, and in the Atlantic and the Indian Oceans, the number of selected points does not enable us to provide a coherent determination of the LAB depth.

For all of the oceanic regions, the shear wave velocity proxy patterns are compatible with the $1300^{\circ} \mathrm{C}$ isotherm of the MCK model. The Pacific Ocean pattern can also be compatible with the $1100^{\circ} \mathrm{C}$ isotherm of the HSC model for the deeper old lithosphere (in the range of its error bars). The Atlantic and Indian Ocean profiles indicate a flattening of the thickening of the oceanic lithosphere from $\sim 75-80$ Myr, reaching 110-120 km, which shows that neither is also compatible with the HSC model. The Pacific profile inferred from the azimuthal anisotropy proxy has an age-dependent shape with deeper and more dispersive values than the shear velocity proxy (up to $\sim 130-135 \mathrm{~km}$ deep), although the variance of this proxy is very large.

\section{Indian Ocean}
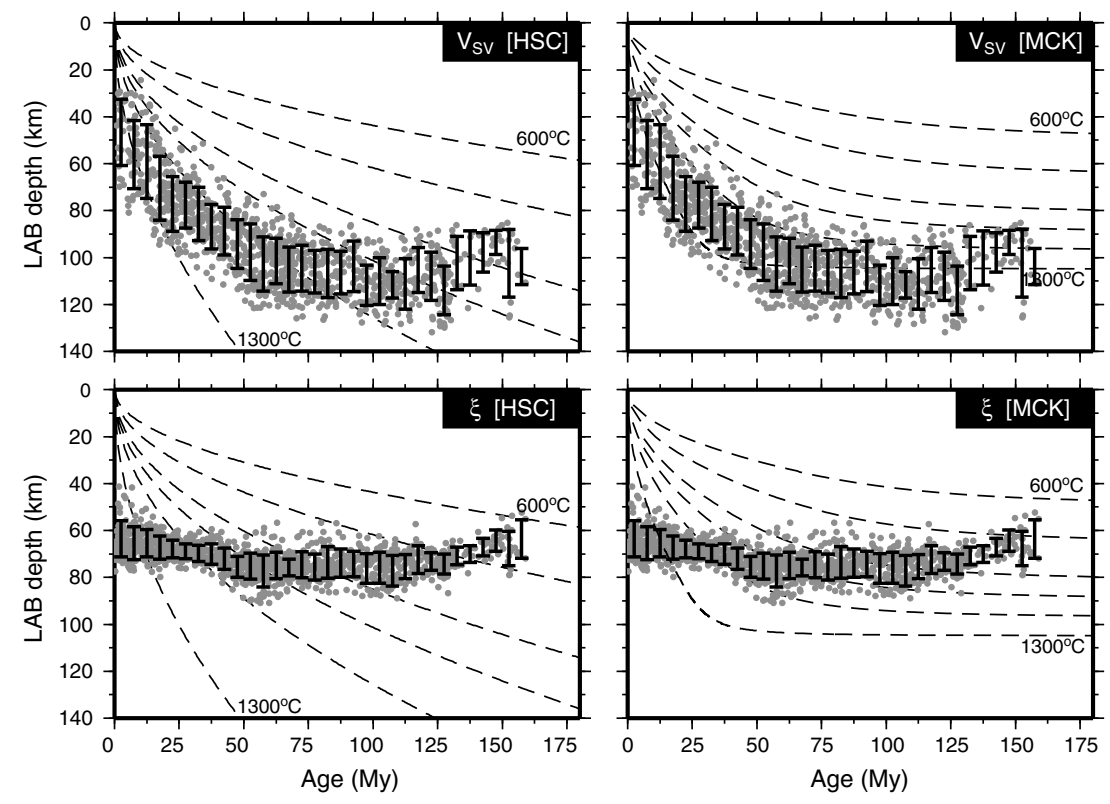

Figure 15. Same as Figure 13 but for the Indian Ocean. 
The influence of partial melting in the asthenosphere [Kawakatsu et al., 2009] might be invoked to explain the amplitude of the $V_{S V}$ drop. Also, the deep LAB inferred from the $\psi_{G}$ proxy is consistent with the stronger amplitude of the azimuthal anisotropy in the asthenosphere than in the lithosphere, as reported by Debayle et al. [2005] for oceanic regions.

The most interesting result is the $L A B$ age profile derived from $\xi$. The diagrams associated with the radial anisotropy proxies $\xi$ show a dramatically low age-dependence with a subhorizontal pattern. The Atlantic and Indian Ocean profiles do not show any shallow depths near the ridges, and they are almost horizontal between $70 \mathrm{~km}$ and $80 \mathrm{~km}$, while the Pacific Ocean pattern shows a slight thickening, from $50 \mathrm{~km}$ near the ridges to $80 \mathrm{~km}$ for the old oceanic parts. This can be relatively compatible with the $\sim 1100-1200^{\circ} \mathrm{C}$ isotherms of the MCK model. To first order, the $\xi$ proxy reveals a plate model with an almost constant thickness, which might be related to the rigid plate where the deformation is very small. According to some subsolidus models with grain boundary sliding that is enhanced by water content [Karato, 2012], the LAB in the young ocean will be age-dependent, while it is shallower than $70 \mathrm{~km}$ because the partial melting temperature occurs at depths less than $70 \mathrm{~km}$, where the material is water poor. However, in the old ocean, a shallow LAB $(60-80 \mathrm{~km})$ with a low temperature can occur due to a higher water content. This model predicts a subhorizontal pattern for the LAB.

\section{Conclusions}

Three proxies for the oceanic LAB are defined from our 3-D model: the top of the low vertically polarized shear velocity zone; the top of the radial anisotropy $\xi$ positive anomaly; and the change in the orientation of the fast axis of the azimuthal anisotropy $\psi_{G}$ (only for the Pacific Ocean). The LAB depth distributions from the $V_{S V}$ proxy are basically consistent for the different oceanic regions. As with the LAB depth distributions from the $\xi$ proxy, there is also good consistency between the different oceans.

These results emphasize the two types of patterns of oceanic lithosphere evolution:

1. The shear velocity and azimuthal anisotropy proxies show age-dependent profiles in global agreement with the thermal plate model from McKenzie et al. [2005] (isotherm $1300^{\circ} \mathrm{C}$ ). The velocity drop in the asthenosphere might be explained by partial melting [Kawakatsu et al., 2009].

2. The LAB based on radial anisotropy $\xi$ is characterized by a shallower depth, which defines a subhorizontal interface with very low age dependence. This requires further explanation through other physical mechanisms, such as the water content [Karato, 2012]. This needs to be investigated in more detail to understand how it was formed in less than $30 \mathrm{Myr}$, and why its thickness is almost independent of age.

Acknowledgments

The authors thank J. Trampert, G. Ekström, E. Beucler, M. Ritzwoller, and N. Shapiro for the collected seismic data. This paper has been significantly improved thanks to the detailed reviews of the Associate Editor and two anonymous reviewers. This is IPGP contribution number 3486.

\section{References}

Anderson, D. L., and C. G. Sammis (1969), The low velocity zone, Geofis. Int., 9, 3-19.

Artemieva, I. (2006), Global $1 \times 1$ thermal model TC1 for the continental lithosphere: Implications for lithosphere secular evolution, Tectonophysics, 416, 245-277.

Barrell, J. (1914), The strength of the Earth's crust, Geology, 22, 28-48.

Bassin, C., G. Laske, and G. Masters (2000), The current limits of resolution for surface wave tomography in North America, EOS Trans. AGU, 81, F897.

Beucler, E., E. Stutzmann, and J.-P. Montagner (2003), Surface wave higher-mode phase velocity measurements using a roller-coaster-type algorithm, Geophys. J. Int., 155, 289-307.

Beucler, E., and J.-P. Montagner (2006), Computation of large anisotropic seismic heterogeneities (CLASH), Geophys. J. Int., 165, 447-468. Daly, R. P. (1940), Strength and Structure of the Earth, 1-434, Prentice-Hall, Englewood Cliffs, N. J.

Debayle, E., and M. Sambridge (2004), Inversion of massive surface wave data sets: Model construction and resolution assessment, J. Geophys. Res., 109, B02316, doi:10.1029/2003JB002652.

Debayle, E., B. L. N. Kennett, and K. Priestley (2005), Global azimuthal seismic anisotropy and the unique plate-motion deformation of Australia, Nature, 433, 509-512.

Doin, M. P., and L. Fleitout (1996), Thermal evolution of the oceanic lithosphere : An alternative view, Earth Planet. Sci. Lett., 142, $121-136$. Dziewonski, A. M., and D. L. Anderson (1981), Preliminary reference Earth model, Phys. Earth Planet. Inter., 25, $297-356$.

Eaton, D. W., F. Darbyshire, R. L. Evans, H. Grütter, A. G. Jones, and X. Yuan (2009), The elusive lithosphere asthenosphere boundary (LAB) beneath cratons, Lithos, 109, 1-22, doi:10.1016/j.lithos.2008.05.009.

Ekström, G. (2011), A global model of Love and Rayleigh surface wave dispersion and anisotropy, 25-250 s, Geophys. J. Int., 187, $1668-1686$.

Ekström, G., J. Tromp, and E. W. F. Larson (1997), Measurements and global models of surface wave propagation, J. Geophys. Res., 102, 8137-8157.

Ekström, G., and A. M. Dziewonski (1998), The unique anisotropy of the Pacific upper mantle, Nature, 394, $168-172$.

Ferreira, A. M. G., J. H. Woodhouse, K. Visser, and J. Trampert (2010), On the robustness of global radially anisotropic surface wave tomography, J. Geophys. Res., 115, B04313, doi:10.1029/2009JB006716.

Fishwick, S. (2010), Surface wave tomography: Imaging of the lithosphere-asthenosphere boundary beneath central and southern Africa, Lithos, 120, 63-73. 
Ford, H. A., K. M. Fischer, D. L. Abt, C. A. Rychert, and L. T. Elkins-Tanton (2010), The lithosphere asthenosphere boundary and cratonic lithospheric layering beneath Australia from Sp wave imaging, Phys. Earth Planet. Int., 300, 299-310, doi:10.1016/j.epsl.2010.10.007. Gutenberg, B. (1959), Physics of the Earth's Interior, Elsevier, Academic Press, New York. Herrmann, R. B. (1987), Surface Waves, in Computer Programs in Seismology, vol. iv.

Jones, A. G., I. J. Ferguson, A. D. Chave, R. L. Evans, and G. W. McNeice (2001), Electric lithosphere of the Slave craton, Geology, 29, 423-426.

Karato, S.-I. (2012), On the origin of the asthenosphere, Earth Planet. Sci. Lett., 321, 95-103.

Kawakatsu, H., P. Kumar, Y. Takei, M. Shinohara, T. Kanazawa, E. Araki, and K. Suyehiro (2009), Seismic evidence for sharp lithosphere-asthenosphere boundaries of oceanic plates, Science, 324, 499-502.

Kirkpatrick, S., C. D. Gelatt, and M. P. Vecchi (1983), Optimization by simulated annealing, Science, 220, 671-680.

Kumar, P., X. Yuan, R. Kind, and J. Ni (2006), Imaging the colliding Indian and Asian lithospheric plates beneath Tibet, J. Geophys. Res., 111, B06308, doi:10.1029/2005JB003930.

Marone, F., and B. Romanowicz (2007), Non-linear crustal corrections in high-resolution regional waveform seismic tomography, Geophys. J. Int., 170, 460-467.

McKenzie, D., J. Jackson, and K. Priestley (2005), Thermal structure of oceanic and continental lithosphere, Earth Planet. Sci. Lett., 233, 337-349.

Meier, U., and A. Curtis (2007), Global crustal thickness from neural network inversion of surface wave data, Geophys. J. Int., 169, 706-722. Montagner, J.-P. (1986), Regional three-dimensional structures using long-period surface waves, Ann. Geophys., 4, 283-294.

Montagner, J.-P., and D. L. Anderson (1989), Petrological constraints on seismic anisotropy, Phys. Earth Planet. Inter., 54, 82-105.

Montagner, J.-P., and H. C. Nataf (1986), A simple method for inverting the azimuthal anisotropy of surface waves, J. Geophys. Res., 91, $511-520$.

Montagner, J.-P., and T. Tanimoto (1991), Global upper mantle tomography of seismic velocities and anisotropies, J. Geophys. Res., 96, 20,337-20,351.

Moorkamp, M., A. G. Jones, and S. Fishwick (2010), Joint inversion of receiver functions, surface wave dispersion, and magnetotelluric data, J. Geophys. Res., 115, B04318, doi:10.1029/2009JB006369.

Müller, R. D., W. R. Roest, J.-Y. Royer, L. M. Gahagan, and J. G. Sclater (1997), Digital isochrons of the world's ocean floor, J. Geophys. Res., 102, 3211-3214.

Nataf, H.-C., I. Nakanishi, and D. L. Anderson (1986), Measurements of mantle wave velocities and inversion for lateral heterogeneities and anisotropy: 3. Inversion, J. Geophys. Res., 91, 7261-7307.

Parker, R., and D. Oldenburg (1973), Thermal model of ocean ridges, Nature, 242, 137-139.

Parsons, B., and J. G. Sclater (1977), An analysis of the variation of ocean floor bathymetry and heat flow with age, J. Geophys. Res., 82, 803-827.

Pasyanos, M. E. (2010), Lithospheric thickness modeled from long-period surface wave dispersion, Tectonophysics, 481, 38-50.

Plomerova, J., D. Kouba, and V. Babuska (2002), Mapping the lithosphere-asthenosphere boundary through changes in surface-wave anisotropy, Tectonophysics, 358, 175-185.

Regan, J., and D. L. Anderson (1984), Anisotropic models of the upper mantle, Phys. Earth Planet. Inter., 35, 227-263.

Ritzwoller, M. H., and A. Levshin (1998), Eurasian surface wave tomography: Group velocity, J. Geophys. Res., 103, 4839-4878.

Rychert, C. A., S. Rondenay, and K. M. Fischer (2007), $P$-to- $S$ and $S$-to- $P$ imaging of a sharp lithosphere-asthenosphere boundary beneath eastern North America, J. Geophys. Res., 112, B08314, doi:10.1029/2006JB004619.

Smith, M., and F. Dahlen (1973), The azimuthal dependence of Love and Rayleigh wave propagation in a slightly anisotropic medium, J. Geophys. Res., 78, 3321-3333.

Smith, M., and F. Dahlen (1975), Correction to 'The azimuthal dependence of Love and Rayleigh wave propagation in a slightly anisotropic medium', J. Geophys. Res., 78, 1923-1923.

Stein, C., and S. Stein (1992), A model for the global variation in oceanic depth and heat flow with lithospheric age, Nature, 359, 123-129. Takeuchi, H., and M. Saito (1972), Seismic surface waves, Methods Comput. Phys., 11, 217-295.

Tarantola, A., and B. Valette (1982), Generalized nonlinear inverse problems solved using least squares criterion, Rev. Geophys. Space Phys. $20,219-232$

Tesauro, M., M. K. Kaban, and S. A. P. L. Cloetingh (2008), EuCRUST-07: A new reference model for the European crust, Geophys. Res. Lett., 35, L05313, doi:10.1029/2007GL032244.

Trampert, J., and J. H. Woodhouse (2003), Global anisotropic phase velocity maps for fundamental mode surface waves between 40 and 150 s, Geophys. J. Int., 154, 154-165.

van der Lee, S. (2002), High-resolution estimates of lithospheric thickness from Missouri to Massachusetts, USA, Earth Planet. Sci. Lett., 203, 15-23.

Visser, K., J. Trampert, and B. L. N. Kennett (2008), Global anisotropic phase velocity maps for higher mode Love and Rayleigh waves, Geophys. J. Int., 172, 1016-1032.

Woodhouse, J. H. (1998), The calculation of eigenfrequencies and eigenfunctions of the free oscillations of the Earth and the Sun, in Seismological Algorithms, Computational Methods and Computer Programs, edited by D. J. Doornbos, pp. 321-370, Academic Press, London, U. K.

Woodhouse, J. H., and A. M. Dziewonski (1984), Mapping the upper mantle: Three dimensional modeling of earth structure by inversion of waveforms, J. Geophys. Res., 89, 5953-5986.

Yuan, H., A. M. Romanowiczz, K. M. Fischer, and D. Abt (2011), 3-D shear wave radially and azimuthally anisotropic velocity model of the North American upper mantle, Geophys. J. Int., 184, 1237-1260. 